\title{
Como a Composição das Exportações é Afetada pela Volatilidade Cambial no Brasil*
}

\section{How the Composition of Exports is Affected by the Exchange Rate Volatility in Brazil}

\author{
Maurício Vaz Lobo Bittencourt ${ }^{\mathrm{a}}$ \\ Natássia Zanotto Correa ${ }^{\text {a }}$
}

\begin{abstract}
Resumo: Diante da adoção de um sistema de taxas de câmbio flutuante, após a queda do sistema monetário Bretton Woods, vários países passaram a experimentar o aumento da variabilidade da taxa de câmbio, com diversas consequências para as suas economias. O objetivo central deste estudo consiste em analisar o efeito da volatilidade da taxa de câmbio sobre o comércio brasileiro a nível setorial, dito diferentemente, sobre a composição da pauta de exportação brasileira. Para tanto, considera-se o volume exportado do Brasil para seus principais parceiros comerciais no período de 2001 a 2017, e, posteriormente, realiza-se uma classificação dos produtos em três categorias (básicos, semimanufaturados e manufaturados). A partir de tal agrupamento, a composição da pauta de exportação é definida pela participação de cada categoria de produto no total do volume exportado para os respectivos parceiros. Adicionalmente, essa variável é utilizada como dependente em um modelo gravitacional de comércio, o qual é estimado usando-se os métodos de mínimos quadrados ordinários agrupado, econometria de painel e Poisson pseudo maximum likelihood. Os resultados obtidos indicam que a volatilidade cambial tem um efeito adverso apenas sobre o setor de manufaturas, com efeito positivo nas exportações de produtos básicos e nenhum efeito significativo sobre o comércio de produtos semimanufaturados.
\end{abstract}

Palavras-chave: Volatilidade. Taxa de câmbio. Composição comercial. Exportações setoriais.

\begin{abstract}
Given the adoption of a floating exchange rate, after Bretton Woods' monetary system collapse, many countries started to face an increase on exchange rate variability, with several consequences for their economies. The main objective of this study consists on analyzing the effects of the exchange rate volatility on the Brazilian trade in a sectoral level, saying it differently, on the composition of Brazilian exports. For this purpose, the volume exported from Brazil to its main trading partners from 2001 to 2017 is considered, and, subsequently, the products are classified into three categories (basic, semi-manufactured and manufactured). From such a grouping, the composi-

\footnotetext{
* $\quad$ Os autores gostariam de agradecer o apoio financeiro da Capes e do CNPq e os comentários recebidos dos participantes do 57th Ersa Congress (Groningen) e do XIX Encontro de Economia da Anpec Sul (Florianópolis).

Universidade Federal do Paraná (UFPR), Núcleo de Economia Internacional e Desenvolvimento
} Econômico (NEIDE), Departamento de Economia. Curitiba, Paraná, Brasil.
\end{abstract}


tion of the exports is defined by the share of each product category in the total volume exported to the respective partners. Additionally, this variable was used as dependent in a gravity trade model, which was estimated by a pooled OLS, panel econometrics and PPML. Main results indicate that the exchange rate volatility has an adverse effect only on manufactured sector, with positive impact on exports of basic products and no significant impact on semi-manufactured exports.

Keywords: Volatility. Exchange rate. Trade composition. Sectoral exports.

JEL Classification: F1; F14; F19.

\section{Introdução}

Diante de um contexto marcado, sobretudo, por elevados déficits da economia norte-americana e por crises especulativas, em 1971 o Sistema Bretton Woods perdeu sua conversibilidade do dólar em relação ao ouro e, consequentemente, entrou em colapso. A partir disso, vários países, gradativamente, passaram pela transição de um sistema de taxas fixas de câmbio para um sistema de taxas de câmbio flutuantes (SOARES, 2008). No Brasil, a adoção do câmbio flutuante ocorreu mais tarde, em janeiro de 1999, no segundo governo de Fernando Henrique Cardoso. A partir de então, diante do contexto da ampliação da discussão sobre a volatilidade do câmbio e de seus impactos sobre a competitividade externa, o debate relativo à política cambial tornou-se de extrema importância, em especial para os países em desenvolvimento (HAUSMANN; PANIZZA; STEIN, 2001).

A fim de ampliar a discussão sobre os efeitos da oscilação cambial sobre o comércio brasileiro, a presente pesquisa tem como objetivo central analisar os efeitos da volatilidade da taxa de câmbio, mais especificamente, sobre a composição da pauta de exportação brasileira no período compreendido entre 2001 e 2017. Ressalta-se que tal interesse surge do fato de que, nos últimos anos, a pauta de exportação brasileira vem vivenciando um aumento na participação percentual dos produtos básicos em detrimento da participação dos produtos manufaturados. Dessa maneira, avaliar em que medida as flutuações cambiais afetam o comércio brasileiro a nível setorial torna-se relevante, uma vez que mudanças na composição podem causar alterações na posição dos setores mais competitivos da economia, o que, para Nakabashi, Cruz e Scatolin (2008), consequentemente altera a dinâmica econômica a depender do grau de dinamismo dos setores que estão perdendo ou ganhando força.

Mais especificamente, a importância deste estudo consiste no fato de que, se a volatilidade cambial realmente afeta a estrutura produtiva da pauta exportadora do Brasil, o país pode se tornar mais dependente de uma pauta mais concentrada, 
aumentando sua vulnerabilidade aos choques externos ou, até mesmo, impactando o crescimento econômico. Desse modo, o papel da taxa de câmbio é importante na medida em que altera o resultado do setor externo ao induzir mudanças nos preços relativos dos bens domésticos em relação aos estrangeiros, além de ser importante na determinação da estrutura produtiva da economia, visto que alguns segmentos e setores são mais sensíveis à competitividade via preço. Assim, tal estudo torna-se de extrema importância uma vez que, para Cruz et al. (2007), mudanças na composição causam alterações na posição dos setores mais competitivos da economia, alterando a dinâmica econômica dependendo do grau de dinamismo e encadeamento dos segmentos que estão perdendo e ganhando participação.

Recentemente, uma das preocupações dos analistas econômicos que estudam o cenário internacional, no que diz respeito ao papel das mudanças estruturais sobre o desempenho da economia, é a perda da participação de setores mais dinâmicos no PIB. De acordo com o estudo realizado pela Associação do Comércio Exterior do Brasil (2018), as estatísticas de exportação divulgadas pelo Ministério do Desenvolvimento, Indústria e Comércio Exterior (MDIC)/Secretaria de Comércio Exterior (Secex) revelam que, nos últimos anos, vem ocorrendo um aumento na participação percentual dos produtos básicos em detrimento da participação dos produtos manufaturados, com um aumento maior nas exportações de produtos básicos de 5,1\%, no período 2017-2018, comparativamente ao de manufaturados, que cresceu 2,3\% no mesmo período. De fato, de acordo com dados do MDIC/SECEX (BRASIL, 2018), a participação percentual dos produtos básicos vem crescendo continuamente desde o ano de 2000. Essa realidade está reportada no Gráfico 1, que mostra a participação por fator agregado (básicos, semimanufaturados e manufaturados) no total das exportações desde o ano de 2000 até o ano de 2018. 
Gráfico 1 - Exportação brasileira por fator agregado (\%): 2000 a 2018

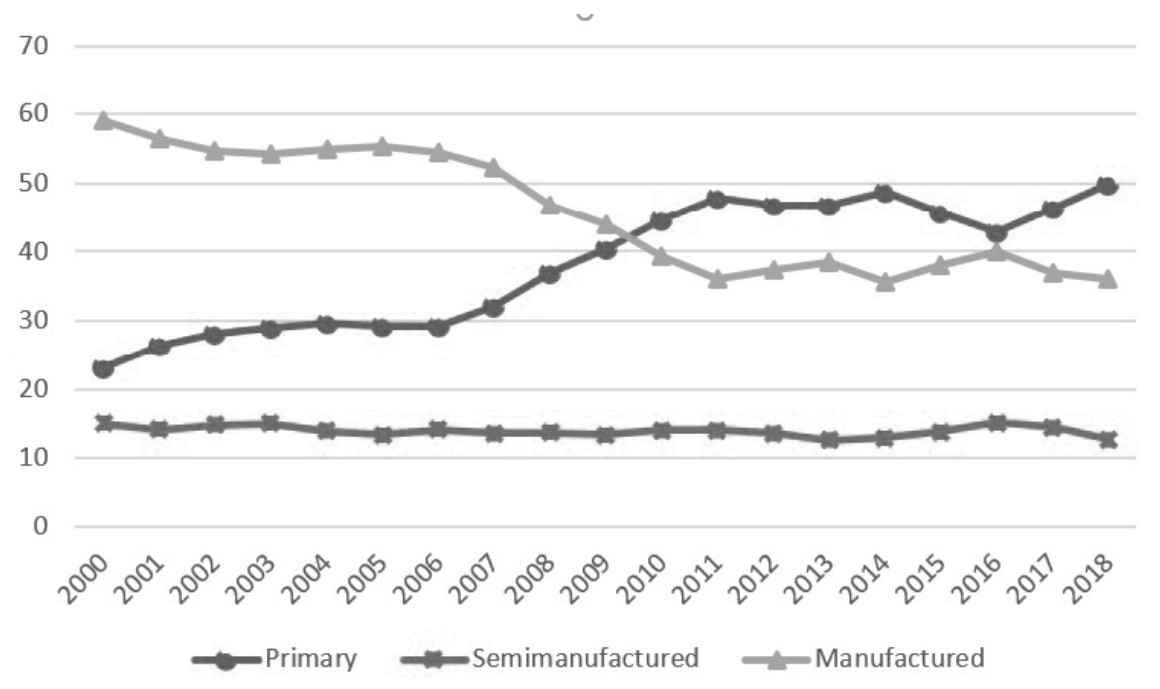

Fonte: Elaboração própria a partir de MDIC/SECEX (BRASIL, 2018).

Somado a isso, um levantamento realizado pela Fundação Centro de Estudos do Comércio Exterior (2015) para determinar o grau de concentração da pauta de exportações brasileira indicou que, no período que vai de 2000 a 2014, o peso de dez produtos da pauta sobre as vendas externas totais passou de $35,8 \%$, no período de 2000 a 2002, para 49,3\% no período de 2012 a 2014. Entre os dez, três produtos básicos estiveram presentes durante todo o período considerado: minério de ferro, soja em grãos e farelo de soja. O que chamou a atenção foi que a participação desses três produtos básicos variou em torno de 14\% nos três primeiros triênios e partiu para uma escalada a partir do triênio 2009-2011, que levou, como dito, a uma presença total de $49,3 \%$, ou seja, praticamente a metade da pauta exportadora brasileira no último período analisado. A brutal concentração ficou ainda mais visível quando os economistas da Fundação Centro de Estudos do Comércio Exterior compararam os dez principais produtos exportados no triênio de 2000-2002 com os dez principais produtos do período de 2011-2014. No primeiro período analisado, a vanguarda era composta por quatro produtos básicos, quatro manufaturados e dois semimanufaturados. Já no período de 2012-2014, desapareceram todos os produtos manufaturados, restando dois semimanufaturados. Todos os demais são básicos (SANTOS, 2015). Assim, se apenas dez produtos compõem quase a metade da pauta de exportação brasileira, sendo que praticamente todos são commodities, é inegável que a receita da pauta exportadora fica altamente dependente de poucos produtos. 
Diante do exposto, cabe considerar que o Brasil pode estar passando por um processo de reprimarização, no qual, de acordo com pesquisa da Associação do Comércio Exterior do Brasil (2018), nos últimos anos o nível de participação dos produtos básicos vem crescendo e é equivalente ao de 1978. Por fim, a Associação do Comércio Exterior do Brasil (2018) tem afirmado que, nos últimos anos, as commodities representam mais de $70 \%$ das exportações brasileiras.

No que tange à estratégia empírica utilizada no presente estudo, considerou-se o volume total de exportações do Brasil para os dez principais parceiros comerciais para um período de 17 anos (2001 a 2017). Em seguida, foi feita uma classificação dos produtos/setores em três categorias: básicos, semimanufaturados e manufaturados. A partir de tal classificação, a composição da pauta de exportação brasileira foi obtida através da proporção que cada setor representa no total do volume exportado por parceiro comercial durante todos os anos. Posteriormente, essa variável foi utilizada como dependente em um modelo gravitacional, cujos parâmetros foram estimados por mínimos quadrados ordinários (MQO) agrupados e, também, por dados em painel (efeitos fixos e efeitos aleatórios) e Poisson pseudo maximum likelihood (PPML). Os resultados obtidos indicam que a volatilidade teve efeito negativo apenas para os produtos manufaturados. Para o comércio de produtos básicos, a volatilidade se mostrou impactar positivamente, enquanto que, para os semimanufaturados, a volatilidade não exerceu nenhuma influência, ou seja, não foi significativa.

Ao mesmo tempo, explorar a influência de outras variáveis ${ }^{1}$ como distância, a qual será uma proxy para custos de transporte, e renda sobre o comércio internacional como objetivo secundário também se torna relevante. No que tange à variável distância, Nilsson (1999) destaca que, por se tratar de uma proxy de custos de transporte, tende a ter um efeito negativo sobre o comércio internacional. Já em relação à renda, Nakabashi, Cruz e Scatolin (2008) sugerem que o seu crescimento tende a favorecer essencialmente a exportação daqueles bens com maior elasticidade-renda.

Além desta introdução, o artigo se divide em mais quatro seções: a segunda apresenta uma breve revisão da literatura acerca da relação entre volatilidade da taxa de câmbio e comércio internacional; a terceira explana a estratégia empírica adotada nesta pesquisa; a quarta realiza a análise e a discussão dos resultados obtidos; por fim, a quinta traça as considerações finais do estudo.

\section{Revisão de Literatura}

Desde o surgimento do regime de câmbio flutuante, em 1973, os efeitos da volatilidade da taxa de câmbio sobre o comércio internacional têm sido tema de

1 Para maiores detalhes a respeito dos dados e da estratégia empírica, ver a seção 3. 
investigações tanto teóricas quanto empíricas. Um dos trabalhos teóricos iniciais ${ }^{2}$ que buscou analisar as implicações da flutuação do câmbio sobre o comércio internacional é o de Clark (1973). Nesse estudo, Clark procura explorar a relação negativa da volatilidade do câmbio e comércio levando em consideração um ambiente no qual as firmas são avessas ao risco. Nesse modelo, a estrutura de mercado é de concorrência perfeita, as firmas só produzem bens destinados à exportação, as quais são pagas em moeda estrangeira. Ademais, o autor supõe que a empresa é pequena e que, dessa forma, seu acesso a mecanismos de cobertura de risco de câmbio é reduzido. Os contratos são acordados em moeda estrangeira, o que faz com seus rendimentos dependam totalmente da taxa de câmbio, e não existem insumos importados. Sinteticamente, a conclusão de tal modelo é que as elevações na volatilidade cambial causam aumento na incerteza dos lucros vindos das exportações, os quais são expressos em moeda local. Devido à hipótese de aversão ao risco das firmas, estas tendem a reduzir a oferta de bens até o ponto em que a receita marginal supere o custo marginal em um montante que seja suficiente para compensar o risco adicional. Isso por que uma empresa com aversão ao risco quer reduzir sua exposição a incertezas, conforme Carmo e Bittencourt (2013).

Baron (1976), ao analisar os efeitos da variabilidade cambial sobre a produção e preços, relaxa a hipótese de uma estrutura de concorrência perfeita com destaque para a opção da moeda a ser utilizada. A firma exportadora, ao faturar em moeda estrangeira, enfrenta risco de preço. A quantidade demandada é conhecida, uma vez que os preços não mudam durante o período de contrato, mas os fluxos de receitas e lucros são incertos. Ao utilizar a moeda doméstica, enfrenta o risco de quantidade demandada, pois o preço para o comprador é incerto, assim como receitas e custos de produção. Desse modo, em ambos os casos, a firma com aversão ao risco quer reduzir sua exposição à incerteza. No entanto, se a moeda estrangeira for acordada nos contratos, quando a incerteza cambial aumenta, firmas avessas ao risco e maximizadoras de lucro elevam o preço. O preço mais elevado reduz lucros esperados, porém aumenta, ao mesmo tempo, a utilidade esperada. No caso da moeda doméstica, sua reação vai depender das propriedades da função de demanda do mercado de destino. Como mostra Baron, se a função for linear, os preços declinam, aumentando a quantidade demandada e, consequentemente, reduzindo a expectativa e variância de lucros.

Diante da conclusão de Clark (1973), a qual foi amplamente difundida durante a década de 1970 e 1980, deve-se atentar para o fato de que o autor usou pressuposições nas quais as circunstâncias envolvidas são extremamente estritas.

2 Dornbusch (1976) foi um dos pioneiros a analisar o papel da flexibilização da taxa de câmbio nas economias no curto e longo prazo, através do que ficou conhecido como modelo de overshooting de câmbio. Do ponto de vista histórico, com a flexibilização das taxas de câmbio com o final do acordo Bretton Woods, inúmeros estudos surgiram como consequência de tal mudança na ordem monetária mundial. 
Da mesma forma, Hooper e Kohlhagen (1978) fazem uma análise semelhante à de Clark (1973), porém aprimorada. Nesse estudo, os autores constroem um modelo para examinar a relação da volatilidade da taxa de câmbio e do comércio entre países, levando em conta, também, a denominação monetária dos contratos, o grau relativo de exposição ao risco dos exportadores e importadores e, diferentemente de Clark (1973), assume a proporção segurada do risco cambial. Para as exportações, os autores afirmam que a variabilidade do câmbio causa uma concentração na quantidade ofertada pelo fato de afetar a parte do lucro que não é segurada (hedge) pela firma. Já no caso das importações, são consideradas como insumos necessários na produção vendida domesticamente. Nesse caso, uma maior volatilidade do câmbio eleva a variância do lucro e desloca a curva de demanda da firma para baixo, levando, consequentemente, a uma redução na quantidade e nos preços. Para Hooper e Kohlhagen (1978), a dimensão do impacto aumenta com a magnitude da elasticidade-preço da curva de demanda e com o grau de aversão e exposição ao risco. A oferta de exportação é modelada em um mercado de estrutura monopolista. Assim como Clark (1973), assume-se que os exportadores vendem toda a sua produção para o mercado externo. Desse modo, um aumento do risco cambial contrai a quantidade ofertada, e, por sua vez, as quantidades são reduzidas e os preços aumentam. Portanto, a forma sintética do modelo mostra uma relação negativa clara entre volatilidade cambial e volume de comércio. Já em relação ao efeito de preços, no entanto, é ambígua. Um aumento do risco cambial causa uma redução nos preços se os importadores suportarem o risco. Isso porque o preço cairá com quedas na demanda por importações. No entanto, se os exportadores tolerarem o risco, o preço subirá como consequência do maior prêmio do risco (ARAÚJO, 2011).

Nessa mesma lógica dos estudos mencionados, Baldwin e Krugman (1989) chamam a atenção para o papel que a incerteza gerada pela maior variabilidade da taxa de câmbio tem sobre o fluxo de comércio através do comportamento dos agentes econômicos envolvidos, já que as firmas avessas a risco tentam se proteger de choques cambiais, afetando negativamente o comércio.

Anos mais tarde, na mesma linha das conclusões anteriores, Dell'Ariccia (1999) analisa, através de um modelo gravitacional e de dados em painel, a relação da incerteza do comportamento do câmbio e do comércio com dados a partir de 15 países da Europa ocidental. A evidência empírica desse trabalho se apoia na visão de que tal instabilidade cambial deprime o comércio internacional. No entanto, de acordo com as conclusões, o efeito negativo da volatilidade do câmbio sobre o comércio internacional é muito pequeno, concluindo que o fluxo comercial teria um maior desempenho, em torno de $10 \%$ a $13 \%$ se tal volatilidade inexistisse. Tal afirmação converge com a conclusão, obtida em anos anteriores, por Gagnon (1993): o autor constrói um modelo teórico e conclui, com base em 
análises numéricas, que o provável impacto da variabilidade da taxa de câmbio dos países industrializados sobre o comércio deve ser pequeno ou insignificante.

De maneira semelhante, a pesquisa de Rose (2000) aponta que a volatilidade do câmbio teria efeitos pequenos, porém prejudiciais sobre a atividade comercial. Afirma, ainda, que o nível de comércio é até três vezes superior entre países de uma união monetária. Isso porque uma moeda única pressupõe mais do que a simples eliminação das volatilidades cambiais. Também reduz os custos de transação, a incerteza e a assimetria de informação. Para Rose (2000), uma moeda única representa um compromisso mais sério e duradouro do que o mero estabelecimento de uma taxa de câmbio fixa entre dois países, o que, na prática, significa ausência de volatilidade cambial. Além disso, completa seu estudo afirmando que uma economia poderia desfrutar de crescimentos significativos se a variabilidade fosse reduzida ou, até mesmo, eliminada entre os parceiros com maior integração econômica. Tal afirmação também foi comprovada posteriormente nos estudos de Rose e Van Wincoop (2001) e Glick e Rose (2002).

No mesmo período, Broda e Romalis (2003) constroem um modelo que explora a dupla causalidade: como o aumento do comércio tem impacto sobre a volatilidade cambial e como a volatilidade cambial impacta o comércio. Em relação a primeira causalidade, apontam que o comércio internacional desempenha um importante papel na redução da instabilidade cambial. No que tange a segunda causalidade, concluem que a instabilidade cambial afeta os produtos comercializados de forma distinta, a depender da natureza desse bem. Sobre esse teste, os resultados foram que, de fato, a volatilidade do câmbio afeta negativamente as exportações, mas que tal efeito negativo é muito pequeno para produtos agrícolas e relativamente grande para produtos industrializados e que, quanto maior for a distância entre parceiros comerciais, maior será a volatilidade cambial.

Mais recentemente, Schnabl (2007) enfatiza ainda que a volatilidade cambial tem tanto efeitos microeconômicos quanto macroeconômicos para o comércio internacional. Do ponto de vista microeconômico, a volatilidade é relacionada a maiores custos de transação, uma vez que há maior incerteza, e proteger-se torna-se custoso. ${ }^{3}$ De maneira indireta, a estabilidade cambial, ao possibilitar que os agentes comparem preços em diferentes países, garante maior transparência. Assim, se eliminada a volatilidade cambial, haverá maior eficiência, produtividade e, por sua vez, maior bem-estar da economia como um todo. Na perspectiva macroeconômica, o autor sugere que a volatilidade da taxa de câmbio de longo prazo afeta a competitividade das indústrias de exportação e importação concorrentes, isto é, em pequenas economias abertas, o comércio é fortemente influenciado pela flutuação cambial.

É valido destacar que, apesar desses estudos apresentados até aqui convergirem para a conclusão de que a incerteza do câmbio tem efeito adverso sobre o

3 Conclusão semelhante à obtida por Baldwin e Krugman (1989). 
comércio internacional, assim como nos trabalhos de Thursby e Thursby (1987), Cushman (1988), Frankel e Wei (1993), Eichengreen e Irwin (1995), não há uma literatura teórica irrefutável sobre a discussão. Portanto, há estudos em que se verificam uma relação ambígua ou positiva entre volatilidade da taxa de câmbio e comércio internacional.

De Grauwe (1988), por exemplo, afirma que o maior efeito-renda sobre o efeito-substituição pode resultar em uma relação ambígua entre variação cambial e comércio. Para o autor, de forma geral, se os exportadores são avessos aos riscos, um aumento da volatilidade cambial pode fazer com que haja aumento na utilidade marginal esperada da venda dos bens exportados e, consequentemente, pode haver um estímulo para as firmas aumentarem a quantidade exportada. Portanto, De Grauwe verifica que o efeito da volatilidade sobre o comércio dependerá da magnitude da aversão ao risco das firmas.

Já Dellas e Zilberfarb (1993) define um modelo teórico com uma pequena economia aberta com um agente doméstico importando, exportando e consumindo dois bens em dois períodos no tempo, em que o mercado de ações é incompleto e o agente toma decisões de comércio com conhecimento incompleto do risco de preço. Os autores afirmam que as instabilidades cambiais resultariam em um grande risco que, ao invés de inibir os agentes econômicos a comercializarem, acabariam criando oportunidades de diversificação do portfólio de risco, o que aumentaria, por sua vez, as expectativas de maiores lucros. Os autores acham que os efeitos da volatilidade sobre o comércio são ambíguos, pois dependem do parâmetro de aversão ao risco.

Seguindo a mesma linha, Coté (1994) faz uma abordagem do mercado de derivativos, cujo comércio é definido como uma opção, a qual se torna mais valorizada na medida em que a incerteza comercial aumenta. Tal efeito ocorreria, sobretudo, em países desenvolvidos e, por sua vez, dotados de um mercado financeiro eficiente. Dessa maneira, os exportadores e importadores de países desenvolvidos possuem melhores condições de acesso ao crédito bem como melhores oportunidades de cobertura, o que, consequentemente, reduz possíveis impactos causados pela instabilidade cambial.

Um resultado muito semelhante ao de Dellas e Ziberfarb (1993) é encontrado no modelo teórico de Broll e Eckwert (1999), o qual apresenta que uma maior volatilidade na taxa de câmbio, sob algumas circunstâncias, pode efetivamente aumentar o volume do comércio. Nesse modelo, os autores consideram uma firma doméstica que atua em mercados competitivos domésticos e/ou internacionais. Quando a moeda é depreciada, ocorre aumento de preço dos produtos exportados e, assim, a empresa obtém maior margem de lucro advindo da exportação. Dessa maneira, a firma responde aumentando a quantidade de produtos exportados. O contrário ocorre quando a moeda, mais tarde, volta a se apreciar. Porém, 
para os autores, a queda na margem de lucro pode ser evitada ao destinar seus produtos para o mercado interno. De acordo com os autores, se a taxa de câmbio oscila substancialmente, os ganhos da exportação em situações favoráveis serão superiores aos ganhos com uma volatilidade mais suave, porque existe a possibilidade de um maior payoff com a depreciação da moeda doméstica. Portanto, Broll e Eckwert (1999) demonstram que a firma pode ser mais lucrativa com maior instabilidade cambial e que o montante médio de exportação pode, também, ser maior com maior volatilidade.

Um estudo aperfeiçoado por Anderson e Wincoop (2003) propõe uma visão diferente a respeito do assunto. Os autores verificam que as relações comerciais entre dois países não são influenciadas apenas pelas variáveis dos países com os quais comercializam, mas também pelas variáveis de seus parceiros comerciais. Em outras palavras, não é apenas a incerteza cambial que afeta o comércio entre o país i e o j, mas também a volatilidade da taxa de câmbio dos países com os quais o país i e/ou j mantêm relações comerciais. Esta influência da incerteza cambial dos parceiros sobre o comércio é denominada efeito third country (efeito terceiro país). Segundo Bittencourt (2004), o efeito terceiro país é o impacto da instabilidade da taxa real de câmbio de um terceiro país no comércio bilateral em análise.

Em um estudo mais recente, Jozsef (2011) analisa o comércio agrícola entre a Hungria e seus parceiros comerciais e obtém um efeito positivo da instabilidade cambial sobre os fluxos comerciais. Para o autor, as implicações de tal efeito positivo da taxa de câmbio sobre a agricultura húngara estão ligadas principalmente pelo fato de que as empresas comerciais de produtos agroalimentares húngaros parecem cobrir os riscos que surgem pela volatilidade cambial utilizando as oportunidades oferecidas pelos mercados a prazo e futuros.

No ano seguinte, Lin (2012) constrói um modelo teórico, considerando firmas heterogêneas, que torna possível verificar o efeito da volatilidade do câmbio sobre o número de produtos exportados e o volume monetário exportado por produto. O modelo parte dos pressupostos de que há uma estrutura com dois países simétricos na qual existem custos de comércio e as firmas locais possuem diferentes níveis de produtividade e que apenas as firmas mais produtivas poderão superar os custos de comércio e comercializar seus produtos no mercado do parceiro comercial. Como as firmas devem determinar os preços de seus produtos e decidir se devem exportar mesmo antes de ter conhecimento da situação da economia mundial, a incerteza cambial deve influenciar tanto a entrada da firma no mercado internacional quanto a quantidade que será exportada. Assim, o modelo sugere que, quando a volatilidade cambial é baixa, os custos do comércio, por sua vez, também serão menores, o que permite que as firmas menos produtivas entrem no mercado internacional. Consequentemente, aumentará a concorrência e o volume de produtos exportados e reduzirá o volume monetário exportado por 
produto. Quando a incerteza cambial for alta, os custos, consequentemente, serão mais elevados também e, assim, somente as firmas que tiverem maior nível produtivo conseguirão espaço no mercado internacional.

Como foi possível verificar, os modelos teóricos que relacionam volatilidade da taxa de câmbio ao comércio internacional não apresentam um consenso. As literaturas acerca do tema indicam que o efeito pode ser negativo, positivo ou, até mesmo, ambíguo. Além disso, vale ressaltar que os resultados podem ser influenciados por diversos fatores, como grupo de países escolhidos, intervalo de tempo observado, tolerância ao risco, bem como quais medidas de risco e volatilidade cambiais foram empregadas, por exemplo. Ou seja, de acordo com Sauer e Bohara (2001), a maneira como fatores - tais como aversão ao risco, oportunidades de hedging, moeda usada nos contratos e presença de outros tipos de riscos - afetam na direção e magnitude entre a incerteza da taxa de câmbio e o comércio é uma questão empírica a ser investigada.

A grande maioria dos estudos, no entanto, é feita através do uso de dados agregados. São poucos os estudos que utilizam como objeto os diversos setores de uma economia, sendo que os poucos que o fazem tratam principalmente do impacto da volatilidade cambial sobre um determinado setor apenas, dentre os quais o setor agrícola é o que mais se destaca pela quantidade de trabalhos empíricos. De acordo com Cho, Sheldon e McCorriston (2002), são poucos os estudos que avaliam os impactos da variabilidade da taxa de câmbio no comércio agropecuário. Algumas das tentativas iniciais na investigação de tais efeitos são os trabalhos de Schuh (1974), Batten e Belongia (1986), Haley e Krissoff (1987) e Bessler e Babula (1987).

\section{Metodologia}

Nesta seção temos uma descrição dos dados, das principais variáveis a serem utilizadas, e a apresentação do modelo empírico a ser estimado.

\subsection{Dados}

Para se identificar o efeito da volatilidade do câmbio sobre a composição da pauta de exportação brasileira, o painel de dados contempla 11 países ao longo de 17 anos (2001 a 2017), sendo eles o Brasil e seus 10 principais parceiros comerciais. ${ }^{4}$ Tal período se justifica por ser o mais recente disponível. O critério para escolha dos principais parceiros comerciais considerados na amostra foi baseado nos dez maiores volumes de exportações do Brasil para os respectivos países, isto

4 São eles: Alemanha, Argentina, Chile, China, Espanha, Estados Unidos, Holanda, Índia, Japão e México. Tais países representaram cerca de $64 \%$ das exportações brasileiras em 2017, sendo que as exportações apenas para China e Estados Unidos totalizaram 38\% do total. 
é, os países que possuem maior peso na pauta de exportação brasileira, obtidos a partir dos dados do World Integrated Trade Solution (WORLD BANK).

\subsubsection{Variável Dependente}

A variável dependente consistirá na composição da pauta de exportação brasileira, $\left(C O M P_{i j t}\right)$. Esta variável será obtida com base no volume de exportações de produtos, ao nível de quatro dígitos do sistema harmonizado oriundos do Comtrade/United Nations Conference on Trade and Development (Unctad), do Brasil para cada parceiro durante os anos considerados. A partir disso, é feita uma classificação dos produtos por fator agregado (básicos, semimanufaturados e manufaturados), baseada em Lall (2000) e, por seguinte, é calculada a proporção de cada setor no volume total exportado para cada ano.

Cabe ressaltar que tal agrupamento, em três grandes classes, leva em conta a maior ou menor quantidade de transformação (agregação de valor) que a mercadoria sofre durante o processo produtivo. Deste modo, os produtos básicos consistem em produtos de baixo valor, normalmente intensivos em mão de obra, cujas cadeias produtivas são simples e sofrem poucas transformações. Já os produtos classificados como semimanufaturados são aqueles que já passaram por algum tipo de transformação, mas que ainda não estão em sua forma definitiva de uso, ou representam manufaturas de baixo nível tecnológico. Em relação aos produtos manufaturados, são aqueles que normalmente incorporam maior tecnologia, com maior valor agregado.

Essa classificação tem sido utilizada no comércio exterior brasileiro desde meados de 1960 e, juntamente com a classificação proposta por Lall (2000), tem sido adotada para mensurar o grau de elaboração da pauta do país. É válido salientar, ainda, que a metodologia por fator agregado foi elaborada pelo setor de nomenclatura da área de estatística da antiga Carteira de Comércio Exterior (Cacex) do Banco do Brasil, órgão responsável à época pela administração do comércio exterior brasileiro. Esta classificação teve por referência a fusão dos critérios do Instituto para Integração da América Latina e do Caribe (Intal) e da Unctad, com adaptações.

De acordo com tal classificação, a amostra totaliza 97 setores/produtos, compreendendo 25 setores/produtos na categoria básicos, 45 na categoria semimanufaturado e 27 como manufaturados. Assim, o número total de observações da amostra é de 16.490 observações (97 setores vezes 10 países vezes 17 anos). Assim, tem-se um painel de dados que evita problemas de viés de agregação (BAHMANI-OSKOOEE; HEGERTY, 2007), no qual a unidade cross-section é representada pela interação setores/produtos e países.

A seguir, apresentam-se os resultados das participações dos produtos básicos (ver Gráfico 1), semimanufaturados (ver Gráfico 2) e manufaturados (ver Gráfico 
3), respectivamente, nas exportações do Brasil para seus dez principais parceiros comerciais, no período compreendido entre 2001 e 2017.

Gráfico 2 - Participação de produtos básicos nas exportações do Brasil para seus principais parceiros entre o ano de 2001 a 2017

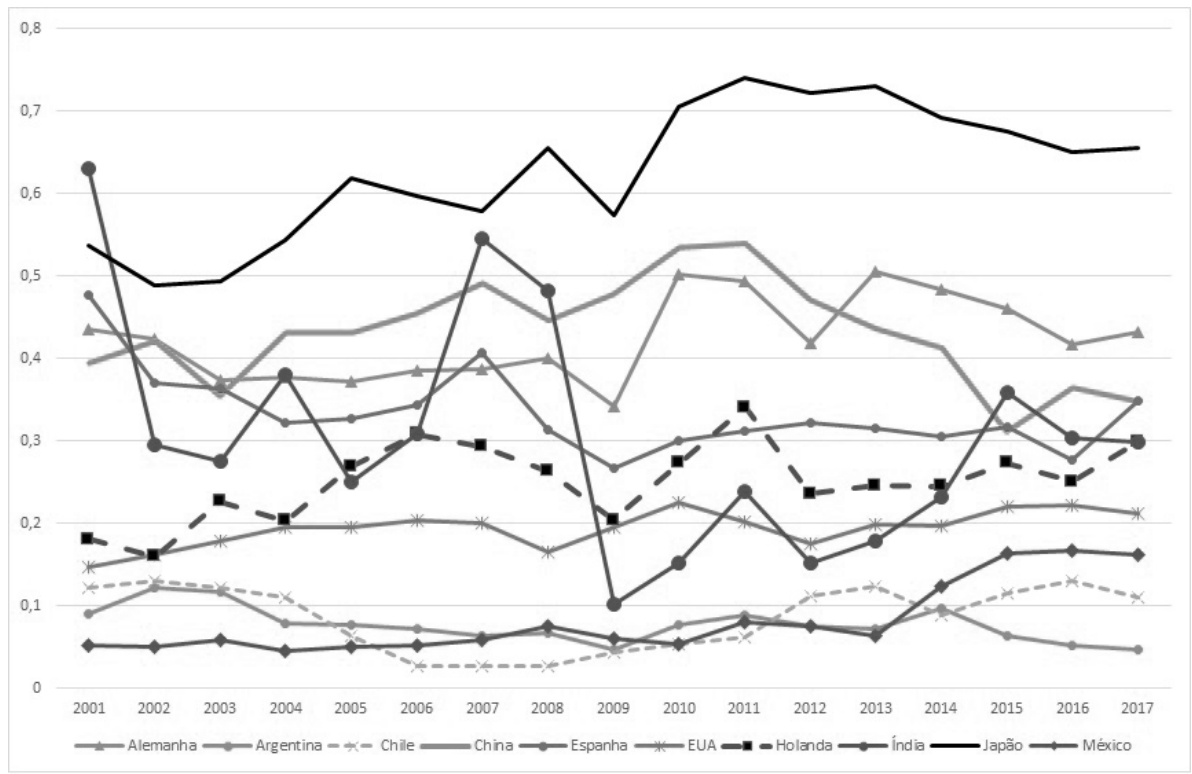

Fonte: Elaboração própria a partir de Comtrade.

Em relação aos produtos básicos, verifica-se que, para o Brasil, aumentou o volume exportado desse tipo de produto, para todo o período, apenas para Estados Unidos, Holanda, Japão e México. Se considerado o período de 2003 a 2011, representando o aumento dos preços internacionais das commodities, percebe-se que houve um aumento nas exportações brasileiras, principalmente para a China e Japão. Dentre os principais importadores de produtos básicos do Brasil, estão Alemanha, China e Japão. 
Gráfico 3 - Participação de produtos semimanufaturados nas exportações do Brasil para seus principais parceiros entre o ano de 2001 a 2017

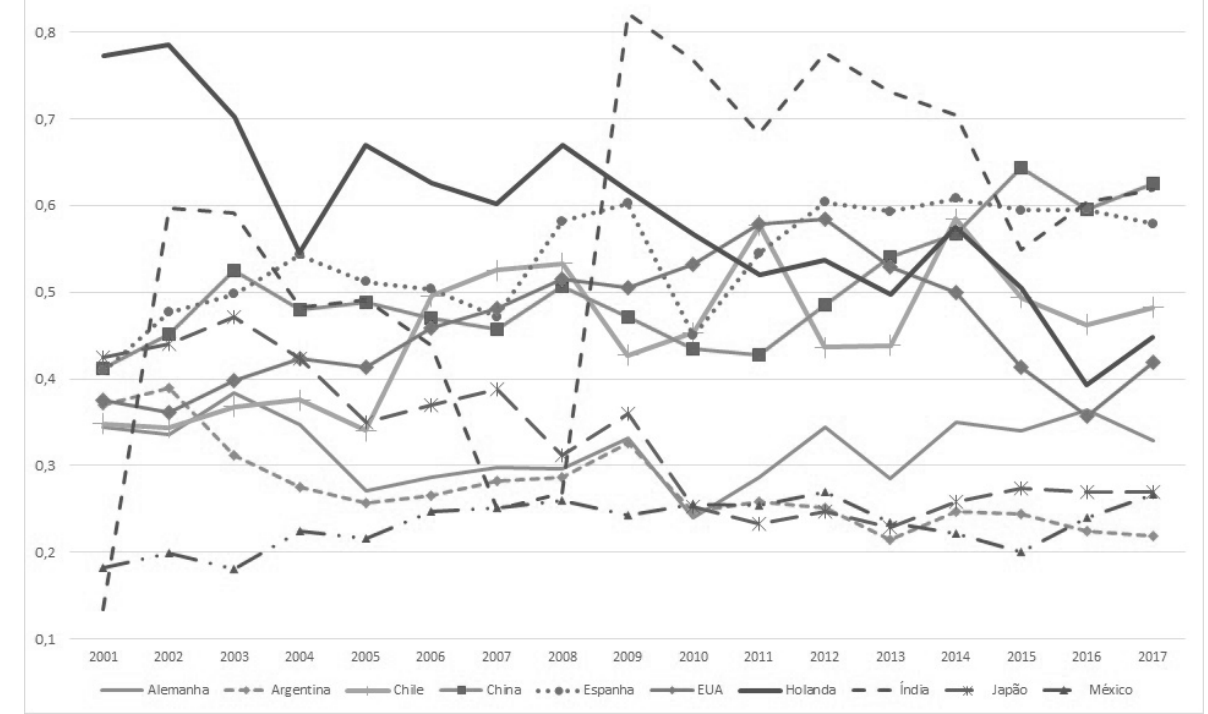

Fonte: Elaboração própria a partir de Comtrade.

Já no que diz respeito aos produtos semimanufaturados, a sua proporção na pauta de exportação brasileira apresenta uma tendência de aumento, com exceção para as exportações para Alemanha, Argentina, Holanda e Japão. Os países que mais compram relativamente produtos semimanufaturados do Brasil são China, Espanha e Índia. 
Gráfico 4 - Participação de produtos manufaturados nas exportações do Brasil para seus principais parceiros entre o ano de 2001 a 2017

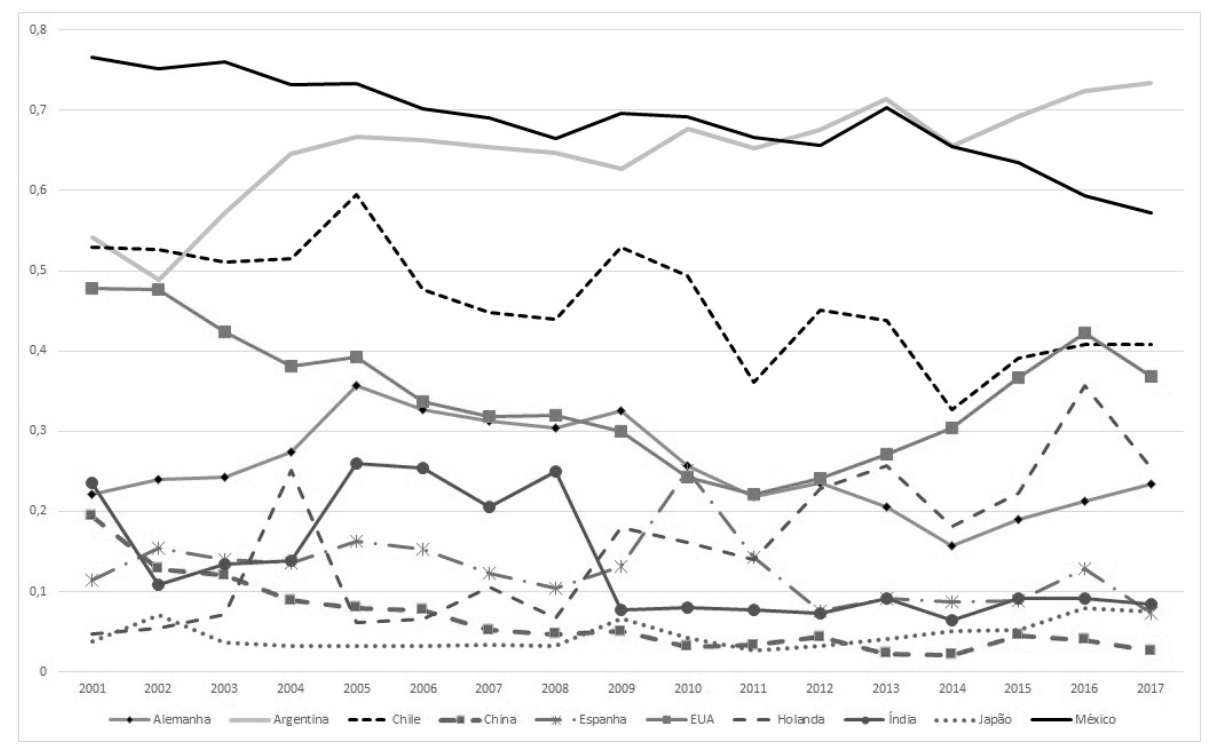

Fonte: Elaboração própria a partir de Comtrade.

No que tange aos produtos manufaturados, é possível observar que, apesar das oscilações, a tendência que predomina entre os parceiros é de queda da proporção dessa categoria de produto até 2011 para a maior parte dos países da amostra, coincidindo com o fim do boom das commodities. O único país em que pode se observar uma elevação de tal proporção por todo o período é a Argentina, a qual apresentou aumento da importação de produtos manufaturados do Brasil. Do total exportado pelo Brasil para Argentina e México, mais de 50\% se caracteriza por produtos manufaturados.

\subsubsection{Variáveis Explicativas}

Conforme discutido na revisão de literatura, a incerteza ${ }^{5}$ de longo prazo da taxa de câmbio é essencial para este estudo. Essa incerteza pode ser obtida através de dois procedimentos usados como proxies da incerteza de longo prazo da taxa de câmbio, o desvio padrão móvel (MSD) e a medida de volatilidade de Perée e Steinherr (PS). ${ }^{6}$

5 Para uma discussão detalhada sobre medidas de volatilidade da taxa de câmbio, ver Lanyi e Suss (1982), Brodsky (1984) e Kenen e Rodrik (1986).

6 Pelo fato das medidas de volatilidade serem usadas como proxies da incerteza da taxa de câmbio real, volatilidade e incerteza são expressões usadas para descrever o mesmo fenômeno neste estudo. 
Na mesma direção dos estudos empíricos de Dell'Ariccia (1999) e Rose (2000), uma maneira de mensurar a volatilidade da taxa real de câmbio bilateral para o tempo $t\left(V O L_{i j l}\right)$ será através do cálculo do MSD da primeira diferença do logaritmo natural da taxa real de câmbio bilateral ${ }^{7}$ anual entre o Brasil (país i) e o país j no período $t-1,{ }^{8}$ para um período de dois e quatro anos. Dessa maneira, tem-se:

$$
V o l_{j, t}=M S D_{j, t}=\sqrt{\frac{\sum_{l=1}^{k}\left(x_{j, t-l}-\bar{x}_{j, t}\right)^{2}}{k-1}}
$$

em que $X_{\mathrm{i}, t}$ é a taxa de câmbio bilateral real, $x_{\mathrm{i}, \mathrm{t}}=\ln \left(X_{\mathrm{ij}, \mathrm{t}}\right)-\ln \left(X_{\mathrm{i}, \mathrm{t}, \mathrm{l}}\right) \mathrm{e} k=2,4$ anos. ${ }^{9} \bar{x}_{\ddot{y}, t}$ é a média de $x_{i, t}$ para os últimos $k$ anos.

A segunda medida de volatilidade da taxa de câmbio real é baseada em Perée e Steinherr (1989), que assume que a incerteza dos agentes econômicos é definida pelas experiências passadas a respeito dos valores máximo e mínimo da taxa de câmbio, os quais são ajustados pela experiência do ano anterior relativa a uma taxa de câmbio de equilíbrio. Desse modo, grandes alterações cambiais ocorridas no passado acabam gerando a volatilidade esperada. Esses autores propõem a seguinte medida da incerteza da taxa de câmbio:

$$
\operatorname{Vol}_{\ddot{j} . t}=\boldsymbol{B}_{j, t}=\frac{\max X_{j, t-k}^{t}-\min X_{j, t-k}^{t}}{\min X_{j, t-k}^{t}}+\left[1+\frac{\left|X_{j, t}-X_{j, t}^{k}\right|}{X_{j, t}^{k}}\right]^{2}
$$

em que $k$ é a duração do período; min $X_{i, j, t}^{t}$ é o mínimo valor absoluto da taxa de câmbio real nos últimos $k$ períodos; $\max X_{i, t, t}^{t}$ é o máximo valor absoluto da taxa de câmbio real nos últimos $k$ períodos; e $X_{i, t, t}^{k}$ é a média dos valores absolutos da taxa de câmbio real para os últimos $k$ períodos. Esse valor é uma proxy da taxa de câmbio real de equilíbrio de longo prazo..$^{10}$ Cada período $k$ nessa análise é representado por cada ano. A justificativa está na ênfase dada aos efeitos de médio a longo prazo da incerteza da taxa de câmbio real.

7 Vale ressaltar que as taxas de câmbio se referem à moeda doméstica de cada país em relação ao dólar.

8 Para se aplicar essa medida de volatilidade, utilizar-se-á a taxa real de câmbio anual do Brasil e dos parceiros no período de 1997 a 2017, a qual foi obtida junto à base de dados do Banco Mundial. O período de tempo é arbitrariamente escolhido para investigar a robustez dos resultados. Conforme Bahmani-Oskooee, Harvey e Hegerty (2012), não existe unanimidade sobre a medida de volatilidade mais adequada. Além disso, não há justificativa teórica para que a volatilidade cambial aumente, diminua ou não produza efeitos sobre o comércio entre os países. Sheldon et al. (2013) sustentam a ideia de que a construção da variável que mensura a volatilidade da taxa de câmbio possui certo grau de arbitrariedade envolvido, tanto no que diz respeito à medida que se deve utilizar quanto sobre qual o período de tempo que esta deve levar em consideração.

De acordo com Mark (1995), não é possível se obter uma medida da taxa de câmbio de longo prazo. Por esta razão, este estudo adota a média aritmética da taxa de câmbio real para todo o período disponível da amostra, de modo a se obter uma aproximação de tal medida de equilíbrio. 
Conforme os modelos teóricos apresentados anteriormente, não há como definir a priori se o coeficiente relacionado a essa variável será positivo ou negativo. Isso porque tanto a direção quanto a magnitude do efeito da volatilidade da taxa real de câmbio sobre a composição da pauta de exportação brasileira deverão ser analisadas empiricamente.

Para melhor visualização, o Gráfico 5 reporta os resultados do cálculo da volatilidade da taxa de câmbio (MSD) ${ }^{11}$ entre o Brasil e seus principais parceiros comerciais no período compreendido entre 2001 e 2017.

Gráfico 5 - Volatilidade da taxa real de câmbio bilateral brasileira $(M S D, k=4)$ do ano de 2001 a 2017

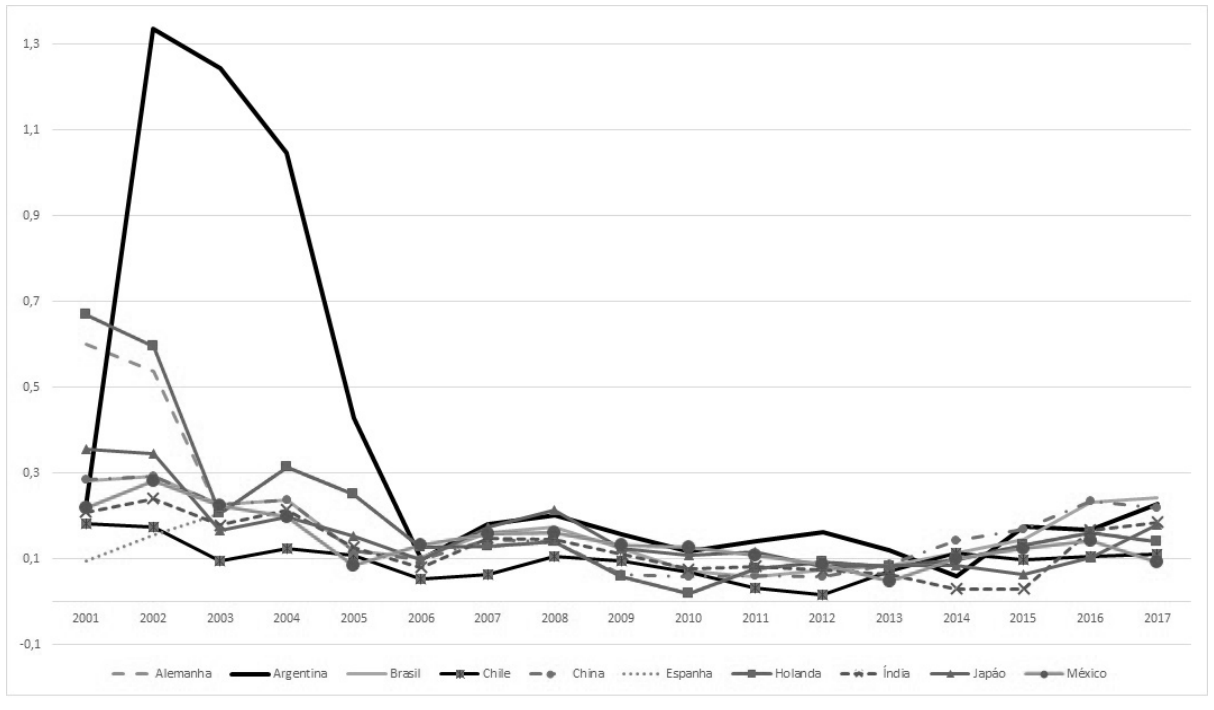

Fonte: Elaboração própria a partir de dados do Banco Mundial.

No ano de 2002, verifica-se alta volatilidade para todos os países, fato que, de acordo com Cerqueira (2011), pode estar relacionado com as instabilidades políticas ocorridas no Brasil, devido às eleições presidenciais. A partir desse período, a volatilidade da taxa real de câmbio bilateral brasileira apresenta uma tendência de queda para a maioria dos países, voltando a subir a partir de 2012-2013.

O Gráfico 6 apresenta os cálculos da volatilidade bilateral do Brasil com seus parceiros comerciais utilizando a medida de volatilidade PS de 2001 a 2017. Nota-se que, apesar da tendência ser próxima à apresentada na medida MSD (ver Gráfico 5), a magnitude de tal medida é maior.

$11 \quad$ Utilizando $k=4$. 
Gráfico 6 - Volatilidade da taxa real de câmbio bilateral brasileira (PS) do ano de 2001 a 2017

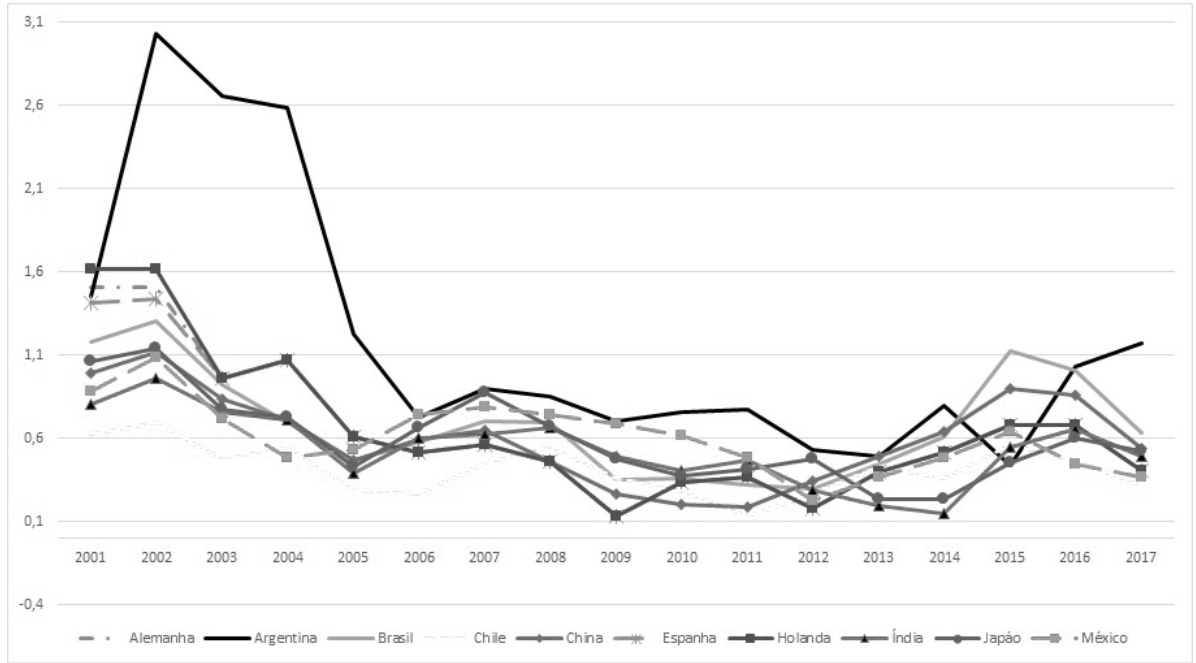

Fonte: Elaboração própria a partir de Banco Mundial.

No que diz respeito às demais variáveis explicativas, define-se:

a) $\operatorname{Ln}\left(P I B_{i t}\right)$ e $\operatorname{Ln}\left(P I B_{j i}\right)$ consistem no logaritmo natural dos PIBs do Brasil (país i) e do país j no tempo $t$. De acordo com os estudos de Cho, Sheldon e McCorriston (2002), Rose (2000), Sauer e Bohara (2001) e Bittencourt, Larson e Thompson (2007), essa variável representa uma proxy para o nível de renda de cada país;

b) Ln (Distij) representa o logaritmo natural da distância geográfica entre o Brasil (país i) e o país j e, segundo Nilsson (1999), representa uma proxy para os custos de transporte. Na mesma direção do estudo de Bittencourt (2004), essa variável diz respeito à distância do grande círculo entre os centros econômicos. Esse método é obtido através da média ponderada das latitudes e longitudes dos principais centros econômicos; ${ }^{12}$

c) $A P C_{i j t}$ representa uma variável binária de controle para o comércio para membros de acordos preferenciais de comércio.

Em relação ao sinal do coeficiente dessas variáveis, de acordo com a equação gravitacional, a qual será apresentada na seção seguinte, espera-se que os PIBs do país i e j impactem positivamente o comércio, enquanto que, em relação à distância, é esperado um efeito negativo sobre a relação comercial entre os países. No entanto, esses impactos podem ser diferentes sobre todas as categorias de

12 A distância do Brasil com seus respectivos parceiros está representada em quilômetros e foi obtida junto à base de dados do Centre D'Etudes Prospectives et d' Informations Internationales (Cepii). 
produtos, seja básico, semimanufaturado ou manufaturado, pois a variável dependente é a composição, e não o fluxo de comércio.

\subsection{Modelo Empírico}

No que tange ao método empírico utilizado nesta pesquisa, uma vez mensurada a composição da pauta de exportação brasileira, a qual será utilizada como variável dependente em um modelo gravitacional de comércio, os demais parâmetros serão estimados através do método de painel de dados.

O modelo gravitacional aplicado à economia internacional foi inicialmente abordado por Tinbergen (1962). A equação gravitacional de comércio é uma analogia à lei da gravidade da física: da mesma maneira que a atração entre dois corpos é proporcional às duas massas e reduz com a distância, a relação comercial entre dois países é proporcional às suas rendas e diminui com a distância geográfica.

Assim, sinteticamente, a formulação básica do modelo gravitacional de comércio determina que os fluxos comerciais entre os países $i$ e $j\left(T_{i j}\right)$ são diretamente proporcionais ao tamanho econômico dos países $\left(Y_{i}\right.$ e $\left.Y_{j}\right)$ e inversamente proporcionais à distância $\left(D_{i j}\right)$. Então, a equação é descrita como:

$$
\mathrm{T}_{\mathrm{ij}}=\left(\mathrm{Y}_{\mathrm{i}} \mathrm{Y}_{\mathrm{j}}\right)^{\alpha / \mathrm{D}_{\mathrm{ij}}^{\beta}}
$$

A partir de trabalhos posteriores, aperfeiçoamentos por meio da inclusão de outras variáveis foram realizados a fim de melhorar o entendimento acerca das trocas comerciais. Neste estudo, para se avaliar os efeitos da volatilidade cambial sobre a composição da pauta de exportação brasileira, será utilizada uma versão modificada da equação gravitacional. Nesse caso, além da renda e da distância, será considerada também, como dito anteriormente, a medida que denota a volatilidade cambial, além de uma variável binária para captar a participação em um acordo preferencial de comércio (APC). Dessa maneira, a formulação empírica da equação gravitacional a ser estimada possui a seguinte especificação:

$\mathrm{COMP}_{\mathrm{ijt}}=\alpha_{0}+\beta_{1} \operatorname{LnVOL}_{\mathrm{ijt}}+\beta_{2} \operatorname{LnPIB}_{\mathrm{it}}+\operatorname{LnPIB}_{\mathrm{jt}}+\beta_{3} \operatorname{LnDIST}_{\mathrm{ij}}+\beta_{4} \mathrm{APC}_{\mathrm{ijt}}$

na qual $\alpha_{0}$ é o intercepto comum para todos os anos e para todas as relações bilaterais.

Como dito anteriormente, a equação gravitacional (equação 4) será estimada a partir da econometria de painel de dados. Nos dados em painel, a mesma unidade de corte transversal (uma família, uma empresa, um indivíduo) é acompanhada ao longo do tempo, ou seja, avalia o impacto de variáveis, ao mesmo tempo, entre unidades de estudo no decorrer do tempo. Dessa forma, aumenta-se o número de observações e, consequentemente, os graus de liberdade da amostra. 
Em síntese, esse método combina dimensões de corte transversal (cross-section) com dados de série temporal, pois a amostra disponível possui três dimensões: tempo, país e setor/produto.

A justificativa para o uso desse método está nas suas principais vantagens, que consistem na aquisição de estimativas mais confiáveis, redução de problemas de multicolinearidade e maior número de graus de liberdade (BITTENCOURT; LARSON; THOMPSON, 2007).

A maneira como as variáveis são incorporadas ao modelo depende do efeito a ser analisado. O painel pode ser estático ou dinâmico. Frees (2004) aponta que a utilização de dados em painel estático deve ser feita quando se deseja analisar de que maneira as variáveis explicativas influenciaram a variável dependente. Em relação ao painel dinâmico, deve ser utilizado quando se deseja fazer previsões sobre o comportamento de uma variável.

É possível estimar o painel estático utilizando-se duas metodologias diferentes: efeitos fixos e efeitos aleatórios. De forma geral, no primeiro considera-se que as variáveis não incluídas no modelo estão correlacionadas com as variáveis incluídas. A estimação é feita através de MQO. Nesse método, são incluídas variáveis binárias para se captar o efeito de cada unidade cross-section de estudo capaz de modificar o intercepto. No que tange ao modelo de efeitos aleatórios, utiliza-se a metodologia de mínimos quadrados generalizados (MQG) para se estimar os coeficientes. De maneira contrária ao modelo de efeitos fixos, assume-se que o erro e as variáveis do modelo estão correlacionados. Além disso, admite-se a não existência de características específicas de cada unidade de estudo.

No que diz respeito à utilização desses métodos, como os efeitos fixos permitem correlação arbitrária entre as variáveis não observadas e as variáveis explicativas enquanto os efeitos aleatórios não a permitem, os efeitos fixos são largamente considerados um instrumento mais convincente para estimar efeitos ceteris paribus.

É válido destacar que o teste de Hausman pode ser usado na decisão entre a utilização de painel com efeitos fixos ou aleatórios. Basicamente, esse teste verifica se existe alguma correlação entre o componente do erro e os regressores. Para isso, o teste compara os coeficientes estimados do modelo com efeitos fixos e aleatórios. Dessa maneira, a ideia por trás do teste de Hausman é que ambos os estimadores, de efeito fixo e aleatório, são consistentes se não houver correlação entre as variáveis explicativas e o erro. Se ambos os estimadores forem consistentes, para grandes amostras, então, devem convergir para os verdadeiros valores do parâmetro beta. Ou seja, em grandes amostras, as estimativas de efeitos fixos e aleatórios devem ser semelhantes. Por outro lado, se o erro estiver correlacionado com as variáveis explicativas, o estimador de efeitos aleatórios será inconsistente, enquanto que o estimador de efeitos fixos permanece consistente. Assim, em grandes amostras, o estimador de efeitos fixos converge para os verdadeiros valores 
dos parâmetros, porém o estimador de efeitos aleatórios converge para algum outro valor que não o valor dos parâmetros verdadeiros. De forma sintética, nesse teste, a hipótese nula é que o efeito aleatório é preferível em detrimento do efeito fixo, uma vez que os erros não estão correlacionados com as variáveis explicativas (HILL; ADKINS, 2011).

No entanto, como a amostra contempla 97 setores/produtos e está subdividida em três subamostras (básicos, semimanufaturados e manufaturados), o método PPML será também utilizado nas estimações devido à presença de zeros nas subamostras. Esta abordagem é baseada em Silva e Tenreyro (2006) e apresenta a vantagem de eliminar um possível viés na presença de zeros em modelos log-linearizados, com perda de consideráveis graus de liberdade. Assim, a equação 4 será estimada por quatro métodos econométricos diferentes: $\mathrm{MQO}$ agrupado, painel de efeitos fixos, painel de efeitos aleatórios e PPML, utilizando-se duas medidas de volatilidade distintas, MSD e PS.

\section{Análise dos Resultados}

Inicialmente, cumpre destacar que, para melhor visualização, a Tabela 1 reporta as estatísticas descritivas das variáveis utilizadas na análise empírica, a qual serve como etapa inicial da análise.

Tabela 1 - Estatísticas descritivas para todos os setores

\begin{tabular}{|c|c|c|c|c|c|}
\hline Variável & $\begin{array}{l}\text { Número de } \\
\text { observações }\end{array}$ & Média & $\begin{array}{l}\text { Desvio } \\
\text { padrão }\end{array}$ & Mínimo & Máximo \\
\hline Básicos $\left(\right.$ Comp $\left._{\mathrm{iit}}\right)$ & 4250 & 0,01128 & 0,03779 & 0 & 0,4652 \\
\hline Semimanufaturados $\left(\mathrm{Comp}_{\mathrm{iit}}\right)$ & 7650 & 0,00947 & 0,03468 & 0 & 0,6154 \\
\hline Manufaturados $\left(\right.$ Comp $\left._{\mathrm{iii}}\right)$ & 4590 & 0,01084 & 0,03792 & 0 & 0,5127 \\
\hline Renda Brasil $\left(\ln P I B_{i j}\right)$ & 16490 & 27,9529 & 0,5643 & 26,9537 & 28,5927 \\
\hline Renda parceiro $\left(\ln P I B_{i}\right)$ & 16490 & 28,0476 & 1,3380 & 24,9680 & 30,5958 \\
\hline Distância (ln Dist $\left.t_{i j}\right)$ & 16490 & 9,0121 & 0,6242 & 7,7798 & 9,7971 \\
\hline Volatilidade $\left(M S D_{i i t} \operatorname{com} k=4\right)$ & 16490 & 0,2046 & 0,3468 & 0,0153 & 3,1615 \\
\hline Volatilidade $\left(M S D_{i \mathrm{it}} \operatorname{com} k=2\right)$ & 16490 & 0,0913 & 0,1470 & 0,0013 & 1,7659 \\
\hline Volatilidade $\left(P S_{i j t}\right)$ & 16490 & 0,6564 & 0,4202 & 0,1310 & 3,0282 \\
\hline
\end{tabular}

Fonte: Elaboração própria a partir de Banco Mundial e Comtrade.

Nota: Estimações do software Stata 13.0.

Como exemplo, conforme a Tabela 1, não é surpresa que a média do log natural da renda no Brasil seja inferior à média do log natural da renda dos parceiros comerciais considerados. Adicionalmente, a média calculada pela medida de volatilidade PS é maior que as calculadas utilizando-se a medida MSD. As três 
subamostras consideradas contêm diferentes tamanhos por conter diferentes números de setores/produtos, conforme já mencionado na subseção 3.1.

\subsection{Básicos}

Em relação aos resultados referentes aos produtos classificados na categoria de básicos, na estimação realizada pelo método de $\mathrm{MQO}$ agrupado nem todos os coeficientes estimados apresentaram sinal esperado, uma vez que algumas variáveis apresentaram sinal positivo. Dessa forma, a variável distância, a qual se esperaria sinal negativo, como ressaltado anteriormente, teve impacto significativo e positivo sobre a composição da pauta de exportação brasileira, no que diz respeito aos produtos básicos. O mesmo ocorreu com a variável de volatilidade, ${ }^{13}$ a qual também se mostrou significativa. Assim, o que se observou é que, quanto maior a incerteza cambial, maior tende a ser a proporção da participação de produtos básicos na pauta de exportação brasileira. Tal conclusão contraria Broda e Romalis (2003), que apontam que as commodities são vendidas em mercados organizados, como bolsas internacionais, e, portanto, são afetadas basicamente pelas cotações internacionais, as quais, a grosso modo, dependem da oferta e da demanda. Assim, os autores sugerem que esta categoria de produto não seria impactada pelas oscilações cambiais sofridas pelos produtores ou compradores de tais produtos. Por fim, no que tange às rendas, ambas foram significativas, mostrando, então, que as rendas brasileira e do parceiro comercial têm efeito sobre a composição de produtos básicos na pauta de exportação do Brasil.

Destaca-se que tais resultados foram obtidos a partir do método de MQO agrupados. No entanto, se detectado o problema de heterocedasticidade, tal método não seria mais adequado, uma vez que, segundo Greene (2003), não leva em consideração a não homocedasticidade dos erros, e, portanto, as estimativas, ainda que não viesadas e consistentes, não seriam mais eficientes. O mesmo pode ser dito no caso da presença de autocorrelação dos erros. Dito isso, faz-se necessária a análise dos resultados a partir dos métodos de dados em painel e PPML, através da volatilidade cambial mensurada pelo MSD com $k=4$ e 2 anos, (a) e (b), respectivamente, além do uso da medida PS, com a coluna (c).

Primeiramente, vale ressaltar que o resultado do teste de Hausman indica que os modelos com efeitos fixos e aleatórios não se mostram equivalentes, ou seja, como as estimações por efeitos aleatórios não são consistentes, deve ser dada atenção às estimações em painel obtidas por efeitos fixos (CAMERON; TRIVEDI,

13 Em todas as estimações MQO agrupado nas tabelas 2, 3 e 4, considerou-se a especificação apenas da volatilidade mensurada por MSD com $\mathrm{k}=4$. As outras duas especificações se mostraram igualmente robustas. Maiores detalhes destas estimações podem ser obtidos através de contato com os autores. 
2005). Ainda para o setor de básicos, os resultados, de acordo com esse teste, indicam que os parâmetros associados a todas as variáveis foram estatisticamente significativos. No entanto, nem todos os sinais se apresentaram como esperado. Portanto, o que significa é que, ambas as rendas, dos países i e j, influenciam na composição dos produtos básicos na pauta exportadora no caso das estimações com efeitos fixos, mas somente a renda do parceiro parece afetar a composição das exportações brasileiras pelas estimações de efeitos aleatórios ( $a$ e $b$ apenas). A distância não foi significativa. No entanto, a variável distância foi significativa e com sinal positivo nas estimações por PPML, contrário ao esperado de acordo com Nilsson (1999). Pode-se ver que esse resultado se mostra consistente com o caso do comércio de commodities entre o Brasil e seu maior parceiro comercial, a China. Nos últimos anos, apesar de tão distantes geograficamente, a China se consolidou como principal importador do Brasil, onde, de acordo com os dados do MDIC/SECEX (BRASIL, 2018), a exportação das mercadorias para o país asiático tem sido marcada pela predominância de commodities.

Por fim, direcionando a análise para o foco principal deste estudo, verifica-se que a volatilidade mostrou-se impactar positivamente a composição de básicos na pauta em todas as estimações, sendo esse efeito bastante robusto independentemente do método e da medida de volatilidade adotados. Em outras palavras, a maior incerteza cambial contribuiu para aumentar a proporção de produtos básicos na pauta no período analisado. Diante desse resultado, é possível fazer uma analogia com o resultado do modelo encontrado por Jozsef (2011). Nesse modelo, o autor verifica a existência de uma relação positiva entre a volatilidade cambial e o fluxo comercial de produtos agrícolas, ou seja, básicos. Isso porque, de acordo com Jozsef (2011), esse efeito positivo da variação cambial sobre o comércio desse tipo de produto é explicado pelo fato de que as empresas comerciais desse ramo se protegem de riscos associados à incerteza, utilizando oportunidades oferecidas pelos mercados a prazo e futuros.

Enfim, no que tange aos produtos básicos, todos os resultados das estimações obtidos pelo método de MQO agrupado, por dados em painel de efeitos fixos e aleatórios e estimações por PPML estão reportados na Tabela 2. Em todas as estimações, foi incluída a variável $A P C_{i j t}$, cujo coeficiente não se mostrou significativo em nenhum modelo. 


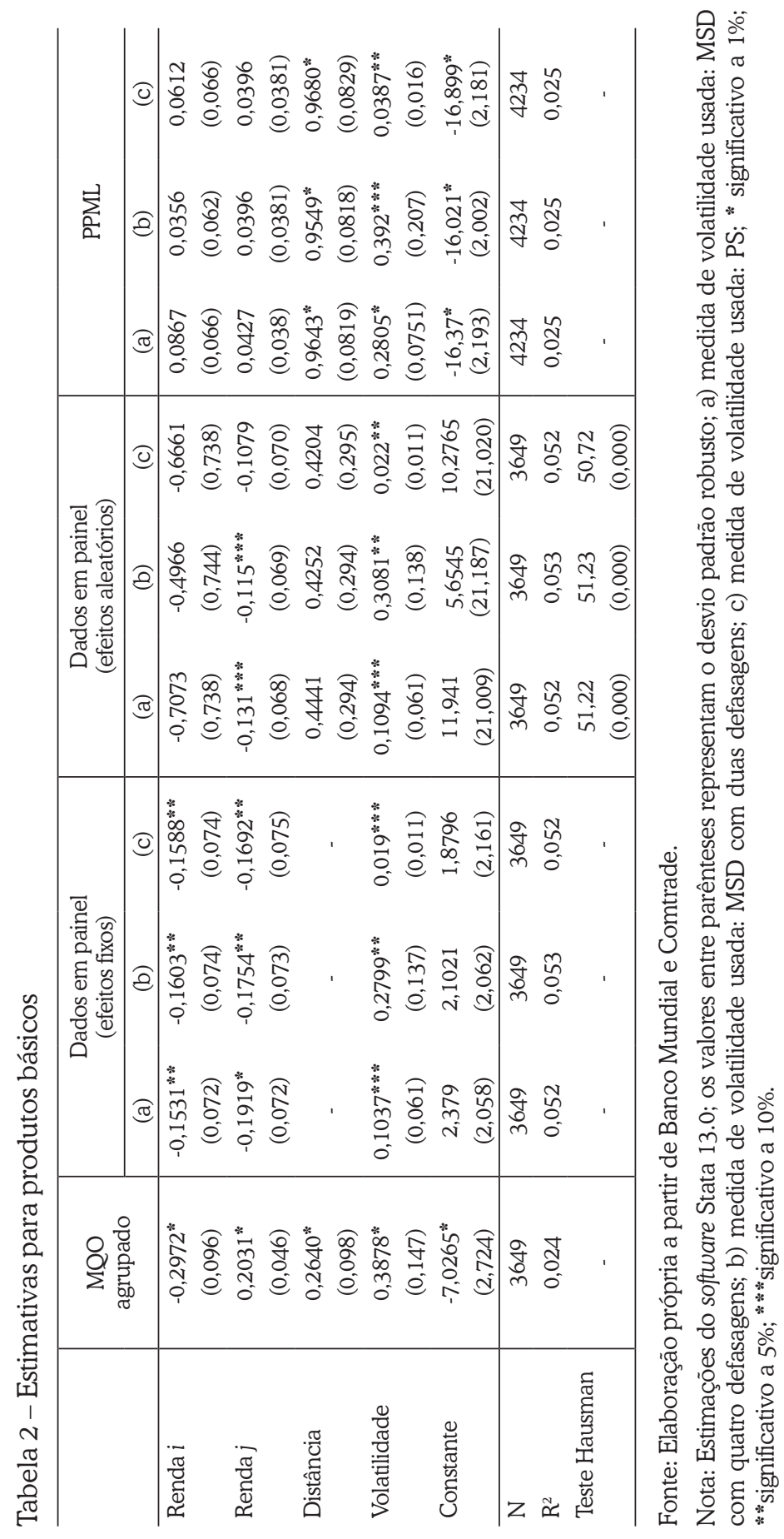




\subsection{Semimanufaturados}

Direcionando a análise para os resultados dos produtos classificados como semimanufaturados em relação aos resultados obtidos por $\mathrm{MQO}$ agrupado, os resultados foram bastante semelhantes aos resultados obtidos para os produtos básicos. No entanto, os coeficientes das rendas dos países i e j se mostraram significativos em todas as estimações, com exceção das estimativas PPML. Além da renda, a variável distância também se mostrou significativa no MQO agrupado e nas estimativas de painel, apresentando sinal negativo. No entanto, os sinais dos coeficientes da distância nos modelos PPML foram positivos e significativos. Essa divergência de sinal é esperada para algumas estimações por características do método PPML, como já fora reportado por Silva e Tenreyro (2006). Em relação à volatilidade, o parâmetro não se mostrou significativo em nenhuma das estimações. Dessa forma, a variação cambial não parece exercer efeito sobre a composição de produtos semimanufaturados na pauta de exportação brasileira.

Concernente à análise dos resultados obtidos por meio de dados em painel, diferentemente do que ocorreu para o caso de produtos básicos, o teste de Hausman não se mostrou significativo, ou seja, não se rejeita a hipótese de que os estimadores oriundos das estimações com efeitos fixos e aleatórios são ambos consistentes, favorecendo a estimação do modelo de efeitos aleatórios em relação ao de efeitos fixos, os quais se tornam ineficientes.

$\mathrm{Na}$ Tabela 3 estão apresentados os resultados de todas as estimações, sendo que em todas as estimações foi incluída a variável $A P C_{\mathrm{ijt}}$, cujo coeficiente não se mostrou significativo em nenhum modelo. 


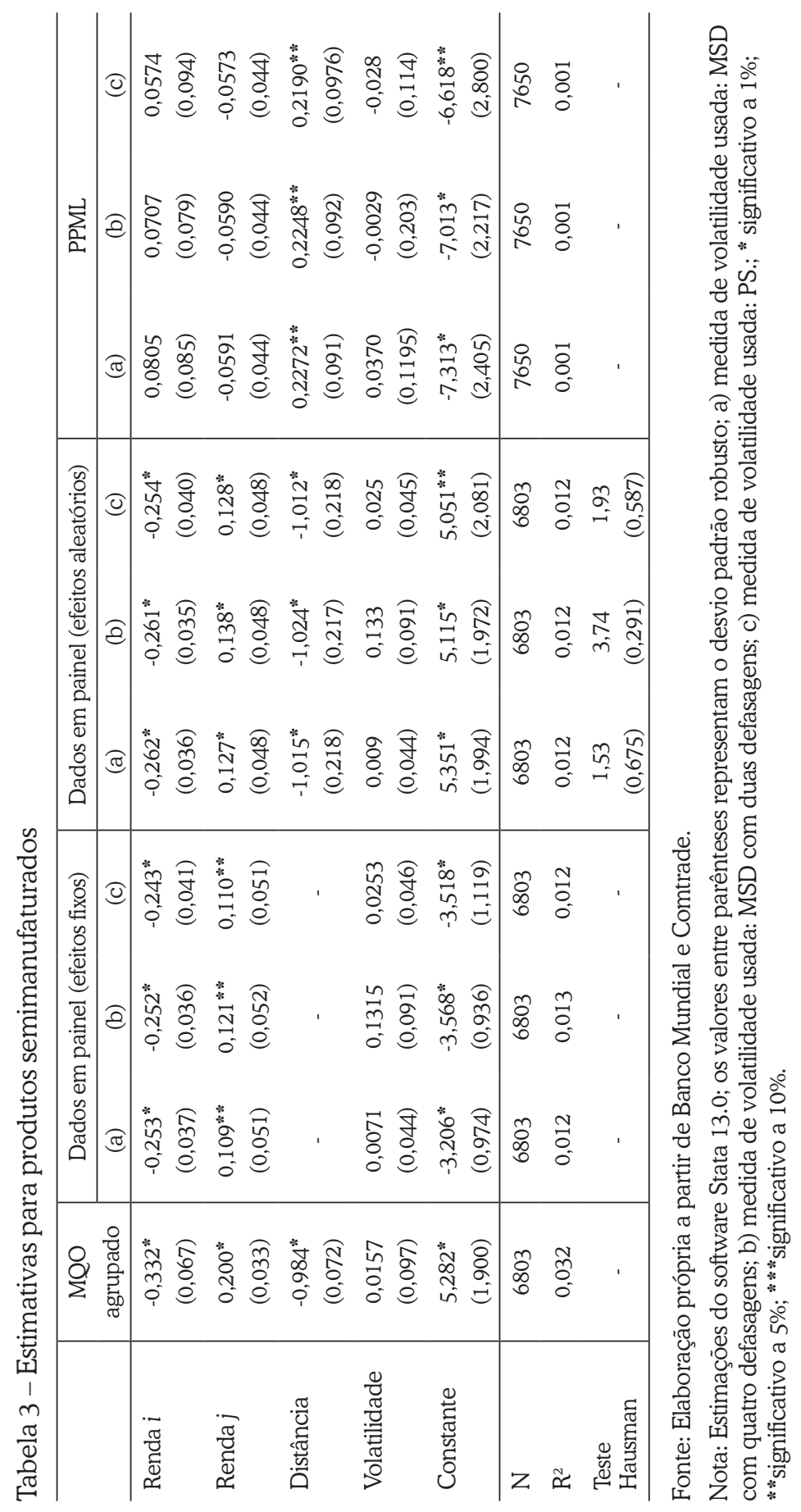




\subsection{Manufaturados}

Por fim, em relação aos resultados obtidos para o setor de manufatura, a estimação por MQO agrupado mostra que as rendas de ambos os países, distância e volatilidade se mostraram significativas. Porém, diferentemente do que ocorreu anteriormente, com sinais negativos para os coeficientes distância e volatilidade. Dessa maneira, o que se pode concluir desses resultados é que, para o caso dos produtos manufaturados, a distância, as rendas do Brasil e do parceiro têm impacto negativo sobre a concentração de produtos manufaturados na pauta exportadora brasileira. Em relação à distância, tal resultado é robusto entre todas as especificações da Tabela 4 e coaduna com o estudo de Nilson (1999), que testa que o efeito negativo da distância geográfica sobre o comércio ocorre porque consiste em uma proxy para os custos de transporte. Portanto, para o caso dos produtos manufaturados, a distância se mostrou um fator negativo, uma vez que torna a exportação desse tipo de produto mais onerosa. Vale destacar que, em relação à última variável, o sinal também está em consonância com o previsto pelo modelo gravitacional.

No entanto, como já ressaltado, para alcançar resultados mais eficientes, torna-se necessária a análise dos mesmos através do método de dados em painel. Assim como para a classe de produtos anterior, as estimativas não se mostraram divergentes, em termos de consistência dos estimadores, entre os efeitos fixos e aleatórios, conforme mostra o teste de Hausman nas três especificações reportadas. No entanto, a não significância do teste indica que o modelo de efeitos aleatórios se mostra mais adequado, já que as estimativas do modelo de efeitos fixos se tornam ineficientes.

No que concerne aos resultados obtidos através desse método, primeiramente os parâmetros associados às variáveis renda do Brasil, distância e volatilidade foram significativos. No que tange aos sinais, todos esses coeficientes mencionados apresentaram sinal negativo. Em outras palavras, a renda brasileira impacta negativamente na composição da pauta exportadora de produtos manufaturados, ou seja, quanto maior a renda do Brasil e de seu respectivo parceiro, menor a proporção de produtos manufaturados que o Brasil exporta para o mesmo, resultado que diverge das predições de Nakabashi, Cruz e Scatolin (2008) e da teoria da equação gravitacional, mas que pode ser justificado pelo maior valor agregado desses produtos, cuja participação no total exportado tende a crescer à medida que a renda doméstica cai, ocorrendo fenômeno semelhante no caso do país importador. Em relação à distância, essa variável obteve o sinal esperado. Para o caso dessa categoria de produtos, quanto maior a distância, menor a proporção exportada pelo Brasil.

No caso das estimações por PPML, todas as variáveis foram significativas, com o adicional de que a renda do parceiro comercial apresenta sinal positivo (como no caso dos resultados do modelo de MQO agrupado). 
Por fim, no que diz respeito à variável em destaque no estudo, a volatilidade apresentou sinal negativo e significativo em todas as especificações e abordagens. Ou seja, a incerteza cambial afeta negativamente a proporção de manufaturados na pauta de exportação brasileira. Portanto, pode-se dizer que tal resultado coaduna com o resultado encontrado por Broda e Romalis (2003), no qual uma maior volatilidade tem impacto significativo sobre produtos com maiores níveis de transformação, ou seja, industrializados. Os autores apontam que os produtos manufaturados possuem diferenças, tanto em relação às suas características quanto em relação à qualidade, e, portanto, tais produtos apresentam custos extras de divulgação, de redes de distribuição bem como de adaptação a mercados externos (idioma, especificações de segurança ou encalços ambientais). Portanto, os autores concluem que a volatilidade cambial poderá tornar todo o processo mais custoso, fato que afeta a lucratividade da cadeia de produção e distribuição que envolve o produto porque os preços são determinados antes da taxa de câmbio ser conhecida, e uma mudança nessa taxa sem dúvida afetará o preço do bem num determinado país, para baixo ou para cima, o que poderá gerar ganhos, mas também perdas se o preço ficar abaixo do considerado ideal ou se a elevação reduzir a demanda por esse bem.

Em todas as estimações foi incluída a variável $A P C_{i j t}$, cujo coeficiente não se mostrou significativo em nenhum modelo. 


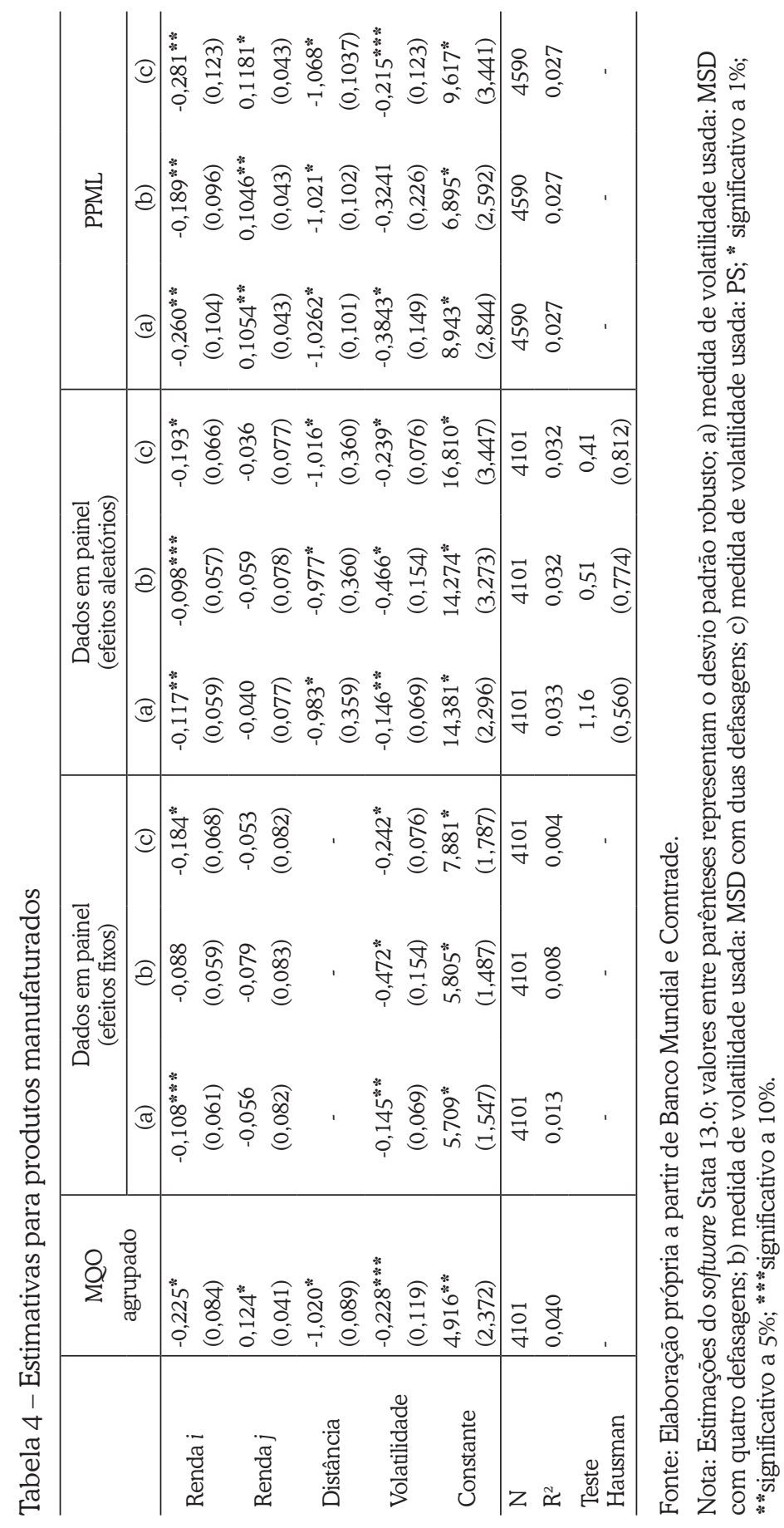


Em suma, a partir dos resultados obtidos, foi possível verificar que o efeito da volatilidade cambial não é igual para todos os (sub)setores. Apesar de não haver uma literatura vasta que aponte objetivamente o efeito da volatilidade a nível desses três setores apresentados na pesquisa, de acordo com os resultados empíricos deste estudo, apenas o setor de manufatura se mostrou sensível negativamente a essa variável, sendo que exatamente o oposto foi obtido com o setor de produtos básicos.

Os resultados reportados nesta seção podem ser sintetizados desta forma:

a) a volatilidade cambial afeta positivamente a concentração das exportações em produtos básicos; essa mesma volatilidade não parece afetar os produtos semimanufaturados e afeta negativamente a concentração das exportações em produtos de maior valor agregado;

b) a renda do Brasil parece contribuir para reduzir a concentração de produtos semimanufaturados e manufaturados, mas com menor ou sem efeito sobre produtos básicos;

c) a renda dos parceiros parece contribuir para aumentar a concentração de semimanufaturados e manufaturados nas exportações brasileiras, porém o inverso ocorre na concentração de produtos básicos;

d) a distância parece contribuir de forma distinta entre os tipos de produtos, reduzindo a concentração no setor de manufaturados, aumentando a concentração no setor de básicos e apresentando ambiguidade com relação aos impactos sobre os semimanufaturados;

e) o papel que a variável acordo preferencial de comércio (APC) teve foi nulo em termos de significância em todas as análises para todos os subsetores considerados.

\section{Considerações Finais}

Através da classificação das exportações brasileiras em produtos básicos, semimanufaturados e manufaturados, baseada em Lall (2000), o principal objetivo deste artigo foi analisar de que maneira a volatilidade cambial afeta o comércio brasileiro a nível setorial e, portanto, a composição da pauta de exportação brasileira, entre 2001 a 2017, considerando as relações comerciais bilaterais entre o Brasil e seus dez maiores parceiros.

Como mencionado, apesar da literatura que relaciona o comércio internacional com alterações na taxa de câmbio ser extensa, não existe total convergência nas conclusões quanto aos efeitos que o aumento da volatilidade da taxa de câmbio pode trazer para o comércio dos países. Uma vasta literatura empírica encontra uma relação negativa, positiva e até mista entre a volatilidade cambial e o comércio. No entanto, no presente artigo, ao se analisar tal relação a nível 
setorial, de acordo com os resultados obtidos pelos métodos empíricos esse efeito se mostrou diferente para cada setor. Em outras palavras, o principal resultado do presente estudo indica que o efeito da volatilidade cambial não se mostrou impactar de maneira equivalente os três setores, o que parece sugerir que políticas de incentivo setorial no Brasil carecem de um olhar mais desagregado e que as autoridades governamentais podem necessitar da formulação de políticas menos agregadas, com a preocupação de que políticas macroeconômicas podem ter efeitos distintos nos diferentes setores da economia.

No que tange aos resultados obtidos, o parâmetro associado à volatilidade cambial impactou positivamente a composição de produtos básicos na pauta de exportação brasileira. De maneira diferente, no caso dos produtos semimanufaturados, essa variável não se mostrou significativa. Ou seja, verifica-se que a incerteza cambial não exerce influência sobre essa categoria de produto. Por fim, em relação aos produtos manufaturados, os resultados obtidos indicaram que as flutuações cambiais possuem um efeito adverso sobre a composição dessa categoria de produto na pauta de exportação brasileira.

Portanto, da mesma maneira que outros estudos apresentados anteriormente, o presente artigo, ao investigar a relação da incerteza cambial sobre o comércio a nível setorial, também não apresentou uma relação objetiva entre essas duas variáveis. Por fim, cabe ressaltar que, apesar das técnicas metodológicas utilizadas, os resultados aqui expostos certamente não abrangem todas as discussões acerca do efeito da volatilidade cambial sobre a composição da pauta de exportação brasileira. Dessa maneira, aprimoramentos podem ser realizados através de um maior número de parceiros comerciais, com a possibilidade também da utilização de outras medidas de volatilidade da taxa de câmbio, empregando outras variáveis que sejam capazes de influenciar o comércio brasileiro a nível setorial, ou até mesmo estimar os resultados através de outras técnicas econométricas. No entanto, a partir desse esforço metodológico, espera-se que esta pesquisa tenha contribuído para impulsionar discussões acerca do tema.

\section{Referências}

ANDERSON, J. E.; WINCOOP, E. V. Gravity with gravitas: a solution to the border puzzle. American Economic Review, v. 93, n. 1, p. 170-192, 2003.

ASSOCIAÇÃO DO COMÉRCIO EXTERIOR DO BRASIL. Revisão da balança comercial 2018. Rio de Janeiro, 2018. Disponível em: http://www.aeb.org.br/. Acesso em: 12 nov. 2020.

ARAÚJO, E.; Volatilidade cambial e crescimento econômico: teorias e evidências para economias em desenvolvimento e emergentes (1980 e 2007). EconomiA, v. 12, n. 2, p.187-213, 2011. 
BAHMANI-OSKOOEE, M.; HARVEY, H.; HEGERTY, S. Exchange-rate volatility and industry trade between the U.S and Korea. Journal of Economic Development, v. 37, n. 1, p. 1-27, 2012.

BAHMANI-OSKOOEE, M.; HEGERTY, S. W. Exchange rate volatility and trade flows: a review article. Journal of Economic Studies, v. 34, n. 3, p. 211-255, 2007

BALDWIN, R. E.; KRUGMAN, P. Persistent trade effects of large exchange rate shocks. Quarterly Journal of Economics, v. 104, n. 4, p. 635-655, 1989.

BARON, D. P. Flexible exchange rates, forward markets, and the level of trade. American Economic Review, v. 66, n. 3, p. 253-266, 1976.

BATTEN, D. S.; BELONGIA, M. T. Monetary policy, real exchange rates and U.S. agricultural exports. American Journal of Agricultural Economics, v. 68, n. 2, p. 422-27, 1986.

BESSLER, D. A.; BABULA, R. A. Forecasting wheat exports: do exchange rates matter? Journal of Business, Economics and Statistics, v. 5, p. 397-406, 1987.

BITTENCOURT, M. V. L. The impacts of trade liberalization and macroeconomic instability on the Brazilian economy. 2004. 262p. Tese (Doutorado) - The Ohio State University, 2004.

BITTENCOURT, M. V. L; LARSON, D. W; THOMPSON, S. R. Impactos da volatilidade da taxa de câmbio no comércio setorial do MERCOSUL. Estudos Econômicos, v. 37, n. 4, p. 791-816, 2007.

BRASIL. Ministério do Desenvolvimento, Indústria e Comércio Exterior. Secretaria de Comércio Exterior. Balança comercial brasileira: acumulado do ano. 2018. Disponível em: https://www.gov.br/produtividade-e-comercio-exterior/pt-br/assuntos/comercio-exterior/estatisticas/balanca-comercial-brasileira-acumulado-do-ano Acesso em: 12 nov. 2020.

BRODA, C.; ROMALIS, J. Identifying the relationship between trade and exchange rate volatility. In: ITO, T.; ROSE, A. K. Commodity prices and markets. Chicago: Chicago Scholarship, 2003.

BRODSKY, D. Fixed versus flexible exchange rates, and the measurement of exchange rate instability. Journal of International Economics, v. 16, p. 295-306, 1984.

BROLL, U.; ECKWERT, B. Exchange rate volatility and international trade. Southern Economic Journal, v. 66, n. 1, p. 178-185. 1999.

CAMERON, A. C.; TRIVEDI, P. K. Microeconometrics: methods and applications. Cambridge: Cambridge University Press, 2005.

CARMO, A. S. S.; BITTENCOURT, M. V. L. O efeito da volatilidade da taxa real de câmbio sobre a diversificação da pauta de exportação do Brasil: uma investigação empírica. In: ENCONTRO NACIONAL DE ECONOMIA, 41, 2013, Foz do Iguaçu. Anais eletrônicos [...]. Foz do Iguaçu: ANPEC, 2013

CERQUEIRA, V. S. Volatilidade da taxa de câmbio real e taxa de juros no Brasil: evidências de um modelo VAR-GARCH-M para o período 1999-2010. Texto para Discussão IPEA, n. 1586, p. 1-30, 2011. 
CENTRE D'ETUDES PROSPECTIVES ET D'INFORMATIONS INTERNATIONALES. GeoDist, Disponível em: http://www.cepii.fr/CEPII/fr/bdd_modele/presentation.asp?id=6. Acesso em: 12 nov. 2020.

CHO, G.; SHELDON, I. M.; McCORRISTON, S. Exchange rate uncertainty and agricultural trade. American Journal of Agricultural Economics, v. 84, n. 4, p. 932-942, 2002.

CLARK, P. B. Uncertainty, exchange risk, and the level of international trade. Western Economic Journal, v. 11, p. 302-313, 1973.

COMTRADE. Statistics database: statistic division. Disponível em: http://www.trademap.org/ Bilateral_TS.aspx. Acesso em: 12 nov. 2020.

CÔTÉ, A. Exchange rate volatility and trade: a survey. Bank of Canada Staff Working Paper, n. 1994-5, 1994.

CRUZ, M. J. V.; NAKABASHI, L.; PORCILE, G.; SCATOLIN, F. D. Uma análise do impacto da composição ocupacional sobre o crescimento da economia brasileira. EconomiA, v. 8, n. 4, p. 55-73, 2007.

CUSHMAN, D. O. US bilateral trade flows and exchange risk during the floating period. Journal of International Economy, v. 24, p. 317-330, 1988.

DELL'ARICCIA, G. Exchange rate fluctuations and trade flows: evidence from the European Union. IMF Staff Papers, v. 46, n. 3, 1999.

DELLAS, H.; ZILBERFARB, B. Real exchange rate volatility and international trade: a reexamination of the theory. Southern Economic Journal, v. 59, p. 651-657, 1993.

DORNBUSCH, R. Expectations and exchange rate dynamics. Journal of Political Economy, v. 84, p. 1161-1176, 1976.

EICHENGREEN, B.; IRWIN, D. A. Trade blocs and the reorientation of trade in the 1930 s. Journal of International Economy, v. 38, p. 1-24, 1995.

FRANKEL, J.; WEI, S. Trade blocs and currency blocs. NBER Working Paper, n. 4335, 1993.

FUNDAÇÃO CENTRO DE ESTUDOS DO COMÉRCIO EXTERIOR. Informativo balança comercial: fluxos de comércio exterior brasileiro. 2015. ano 4, n. 46. Disponível em: http://www. mdic.gov.br/index.php/comercio-exterior/estatisticas-de-comercio-exterior/series-historicas. Acesso em: 12 nov. 2020.

FREES, E. W. Longitudinal and panel data: analysis and applications in the social sciences. Cambridge: Cambridge University Press, 2004.

GAGNON, J. E. Exchange rate variability and the level of international trade. Journal of International Economics, v. 34, n. 3-4, p. 269-287. 1993.

GLICK, R.; ROSE, A. K. Does a currency union affect trade? The time series evidence. European Economic Review, v. 46, n. 6, p. 1125-1151. 2002. 
DE GRAUWE, P. Exchange rate variability and the slowdown in growth of international trade. IMF Working Paper, n. 24, p. 317-330, 1988.

GREENE, W. H. Econometric analysis. 5 ed. Rio de Janeiro: Prentice-hall. 2003.

HALEY, S. L.; KRISSOFF, B. U.S. grain exports and the value of the U.S. dollar. Journal of Agricultural Economics Research, v. 39, n. 2, p. 12-21, 1987.

JOZSEF, F. The effect of exchange rate volatility upon foreign trade of hungarian agricultural products. Studies in Agricultural Economics, v. 113, n. 1, p. 85-96, 2011.

HAUSMANN, R.; PANIZZA, U.; STEIN, E. Why do countries float the way they float? Journal of Development Economics, v. 66, n. 2, 2001.

HILL, R. C.; ADKINS, L. C. Using stata for principles of econometrics. 4 ed. New York: Wiley. 2011.

HOOPER, P.; KOHLHAGEN, S. W. The effect of exchange uncertainty on the prices and volume of international trade. Journal of the Japanese and International Economy, v. 8, p. 483-511, 1978.

KENEN, P.; RODRIK, D. Measuring and analysing the effects of short-term volatility in real exchange rates. Review of Economics and Statistics, v. 68, n. 2, 1986.

LALL, S. The technological structure and performance of developing country manufactured exports, 1985-1998. QEH Working Paper Series, v. 44, 2000.

LANYI, A.; SUSS, E. Exchange rate variability: alternative measures and interpretation. IMF Staff Papers, v. 29, n. 4, p. 527-560, 1982.

LIN, C. Exchange rate uncertainty and trade. The B.E. Journal of Macroeconomics, v. 12, n. 1, p. 1-35, 2012.

MARK, N. Exchange rates and fundamentals: evidence on long-horizon predictability. The American Economic Review, v. 85, n. 1, p. 201-218, 1995.

NAKABASHI, L.; CRUZ, M. J. V.; SCATOLIN, F. D. Efeitos do câmbio e juros sobre as exportações da indústria brasileira. Revista de Economia Contemporânea, v. 12, n. 3, 2008.

NILSSON, L. Two-way trade between unequal partners: the EU and the developing countries. Weltwirtschaftliches Archiv, v. 135, n. 1, p. 102-127, 1999.

PERÉE, E.; STEINHERR, A. Exchange rate uncertainty and foreign trade. European Economic Review, v. 33, n. 6, p. 1241-1264, 1989.

ROSE, A. K. One money, one market: estimating the effect of common currencies on trade. NBER Working Paper Series, n. 7432, 2000.

ROSE, A. K.; VAN WINCOOP, E. National money as a barrier to international trade: the real case for currency union. American Economic Review, v. 91, n. 2, p. 386-390. 2001. 
SANTOS, C. Concentração da pauta de exportações brasileira no complexo da soja, em minério de ferro e petróleo bruto reduzirá capacidade de gerar superávit comercial em 2015. Revista Conjuntura Econômica - FGV, março de 2015.

SAUER, C.; BOHARA, A. K. Exchange rate volatility and exports: regional differences -between developing and industrialized countries. Review of International Economics, v. 9, n. 1, p. 133-152, 2001.

SCHNABL, G. Exchange rate volatility and growth in small open economies at the Emu periphery. European Central Bank Working Papers, n. 773, 2007.

SCHUH, G E. The exchange rate and U.S. agriculture. American Journal of Agricultural Economics, v. 56, n. 1, p. 1-13, 1974.

SHELDON, I.; MISHRA, S. K.; PICK, D.; THOMPSON, S. R. Exchange rate uncertainty and US bilateral fresh fruit and fresh vegetable trade: an application of the gravity model. Applied Economics, v. 45, n. 15, p. 2067-2082, 2013.

SILVA, J. M. C. S.; TENREYRO, S. The log of gravity. The Review of Economics and Statistics, v. 88, n. 4, p. 641-658, 2006.

SOARES, R. O. Inflação, exportação e crescimento econômico: as experiências do México e Brasil durante o regime de câmbio flutuante. 2008. Dissertação (Mestrado) - Universidade Federal de Pernambuco, Recife, 2008.

THURSBY, J. G.; THURSBY, M. C. Bilateral trade flows, the Linder hypothesis and exchange rate risk. Review of Economics and Statistics, v. 69, n. 3, p. 488-495, 1987.

TINBERGEN, J. Shaping the world economy: suggestions for an international economic policy. New York: Twentieth Century Fund, 1962.

WORLD BANK. World Integrated Trade Solution. Homepage. [S. l.], Disponível em: http:// wits.worldbank.org/. Acesso em: 12 nov. 2020.

\section{Autor correspondente:}

Maurício Vaz Lobo Bittencourt

Recebido em: 28/06/2018.

E-mail:mbittencourt@ufpr.br 